\title{
1 Application of ${ }^{36} \mathrm{Cl}$ as a dating tool for modern groundwater
}

2

3 Yuki Tosaki a,b,*, Norio Tase a, Gudrun Massmann ${ }^{\text {c }}$, Yasuo Nagashima ${ }^{\text {b }}$, Riki Seki ${ }^{\text {b }}$, Tsutomu

4 Takahashi ${ }^{\text {b }}$, Kimikazu Sasa ${ }^{\text {b }}$, Keisuke Sueki ${ }^{\text {b }}$, Takeshi Matsuhiro ${ }^{\text {b }}$, Taichi Miura ${ }^{\text {d, }}$ Kotaro

5 Bessho $^{\mathrm{d}}$, Hiroshi Matsumura ${ }^{\mathrm{d}}$, Ming $\mathrm{He}^{\mathrm{e}}$

6

7

8

9

10

11

${ }^{a}$ Geoenvironmental Sciences, Graduate School of Life and Environmental Sciences, University of Tsukuba, Tsukuba, Ibaraki 305-8572, Japan

${ }^{\text {b }}$ AMS Group, Tandem Accelerator Complex, University of Tsukuba, Tsukuba, Ibaraki 305-8577, Japan

${ }^{\mathrm{c}}$ Institute of Geological Sciences, Department of Earth Sciences, Free University of Berlin, Malteserstr. 74-100, 12249 Berlin, Germany

${ }^{\mathrm{d}}$ Radiation Science Center, High Energy Accelerator Research Organization (KEK), Tsukuba, Ibaraki 305-0801, Japan

${ }^{\text {e }}$ Department of Nuclear Physics, China Institute of Atomic Energy, P.O. Box 275 (50), Beijing 102413, China

${ }^{*}$ Corresponding author:

Yuki Tosaki

Geoenvironmental Sciences, Graduate School of Life and Environmental Sciences, University of Tsukuba, Tsukuba, Ibaraki 305-8572, Japan

Tel.: +81-29-853-6871; fax: +81-29-853-6871; E-mail address: tosaki@tac.tsukuba.ac.jp

Nuclear Instruments and Methods in Physics Research B, 259, 479-485. 


\section{Abstract}

2 The ${ }^{36} \mathrm{Cl} / \mathrm{Cl}$ ratios of groundwater samples were measured by AMS in order to investigate 3 the potential use of ${ }^{36} \mathrm{Cl}$ as a dating tool for modern groundwater. Groundwater samples were 4 obtained from several piezometers in the Oderbruch in northeastern Germany. The shallow 5 confined aquifer of the area is mainly recharged by the infiltration from the River Oder. From 6 the results of measurements, the pre-bomb and the recent background ${ }^{36} \mathrm{Cl} / \mathrm{Cl}$ ratios in the basin 7 of the Oder were estimated to be $7-9 \times 10^{-14}$. The ${ }^{36} \mathrm{Cl}$ fallout values estimated from the ${ }^{36} \mathrm{Cl} / \mathrm{Cl}$ 8 ratios of the Oderbruch samples, which were dated by the ${ }^{3} \mathrm{H} /{ }^{3} \mathrm{He}$ method, show good agreement 9 with Dye-3 ice core data. These results suggest that the distribution of ${ }^{36} \mathrm{Cl}$ in groundwaters reflects the influence of the ${ }^{36} \mathrm{Cl}$ bomb pulse. This, in turn, suggests that the distribution of ${ }^{36} \mathrm{Cl} / \mathrm{Cl}$ in modern groundwaters could reveal groundwater ages and flow systems in a region.

PACS: 92.40.Kf; 91.67.Qr; 93.30.Ge; 06.60.Ei

Keywords: Bomb-produced ${ }^{36} \mathrm{Cl}$; Accelerator mass spectrometry (AMS); Modern groundwater; Residence time; Groundwater dating; Environmental tracer

\section{Introduction}

Tritium $\left({ }^{3} \mathrm{H}\right)$ has been one of the most useful environmental tracers for dating of modern groundwater (age $\sim 50$ years) [1,2]. Since large quantities of ${ }^{3} \mathrm{H}$ were produced during atmospheric thermonuclear testing, ${ }^{3} \mathrm{H}$ concentrations in precipitation reached a peak around 1963, resulting in a "bomb pulse" in the hydrological cycle. However, due to the short half-life of ${ }^{3} \mathrm{H}$ (12.33 years [3]), the ${ }^{3} \mathrm{H}$ bomb pulse has been attenuated significantly through radioactive decay. This leads to a need for another tracer or dating method applicable in modern groundwater studies. Recently, several tracers have been successfully utilized; e.g., tritiogenic ${ }^{3} \mathrm{He}\left({ }^{3} \mathrm{He}\right.$ produced by ${ }^{3} \mathrm{H}$ decay; ${ }^{3} \mathrm{H} /{ }^{3} \mathrm{He}$ method) [4], CFCs (Chlorofluorocarbons) [5], $\mathrm{SF}_{6}$ [6] and ${ }^{85} \mathrm{Kr}$ [7]. Tritiogenic ${ }^{3} \mathrm{He}$ and CFCs, especially, are extensively used in groundwater studies. It is of note that when applied in the field, these tracers require complete isolation of the samples from the atmosphere because they are gas tracers. 
2 Bentley et al. [8]. ${ }^{36} \mathrm{Cl}$ is a long-lived radioisotope of chlorine with a half-life of $3.01 \times 10^{5}$ years

3 [3]. Natural ${ }^{36} \mathrm{Cl}$ is mainly produced in the following three ways: (1) cosmic-ray spallation of

$4 \quad{ }^{40} \mathrm{Ar}$ in the atmosphere; (2) cosmic-ray spallation of $\mathrm{K}$ and $\mathrm{Ca}$, and neutron activation of ${ }^{35} \mathrm{Cl}$ near the surface rocks and (3) neutron activation of ${ }^{35} \mathrm{Cl}$ in the deep subsurface [9]. Amongst these three sources, (1) cosmic-ray spallation in the atmosphere is the main natural source of ${ }^{36} \mathrm{Cl}$ in groundwater. The ${ }^{36} \mathrm{Cl}$ produced in the atmosphere is mixed with marine-derived stable chlorine (from seaspray) and falls onto the earth's surface, with the greatest fallout occurring at mid-latitudes [9].

In addition, significant amounts of ${ }^{36} \mathrm{Cl}$ were produced by neutron activation of ${ }^{35} \mathrm{Cl}$ in seawater during thermonuclear testing on small islands or on barges (primarily between 1954 and 1958), and this bomb- ${ }^{36} \mathrm{Cl}$ was injected into the atmosphere [10]. Fallout of this bomb- ${ }^{36} \mathrm{Cl}$ has been preserved in ice cores, e.g., the Dye-3 cores from Greenland $[11,12]$, show a ${ }^{36} \mathrm{Cl}$ peak in the late 1950s (several years prior to the ${ }^{3} \mathrm{H}$ peak). The bomb-pulse ${ }^{36} \mathrm{Cl}$ is thought to have a latitudinal distribution with greatest deposition at mid-latitudes [10].

Chlorine is geochemically conservative in hydrological cycle because it has a high electron affinity and it exists primarily as $\mathrm{Cl}^{-}$in the environment, except under low $\mathrm{pH}$ condition [9]. This makes chlorine an ideal tracer in hydrology and also makes sampling for ${ }^{36} \mathrm{Cl}$ very straightforward. With these advantages, and its long half-life, ${ }^{36} \mathrm{Cl}$ has been applied to the dating of very old groundwater in such regions as the Great Artesian Basin of Australia [13] and the Milk River Aquifer of Canada [14].

In the case of the ${ }^{36} \mathrm{Cl}$ bomb pulse, the long half-life makes decay attenuation negligible on the time scale of several decades to centuries (in contrast to ${ }^{3} \mathrm{H}$ ). Thus, the ${ }^{36} \mathrm{Cl}$ bomb pulse provides a potential dating tool covering the last $\sim 50$ years. Although it has been applied to studies of the unsaturated zone (soil waters) to estimate recharge rates $[15,16]$, there are few studies applying the ${ }^{36} \mathrm{Cl}$ bomb pulse to groundwaters [17]. Therefore, in this study we attempt to relate ${ }^{36} \mathrm{Cl}$ content variations to groundwater residence times and investigate the potential use of the ${ }^{36} \mathrm{Cl}$ bomb pulse as a dating tool for modern groundwater. 


\section{2. Materials and methods}

\section{$3 \quad$ 2.1. Study sites and groundwater sampling}

4 The Oderbruch is a large polder (reclaimed land) area which is located in northeastern part 5 of Germany (Fig. 1). At the east side of the area, the Oder flows northward on the border 6 between Germany and Poland into the Baltic Sea. The Oder begins in the Oder Mountains of the

7 Czech Sudeten in the eastern part of Czech Republic. Hydrogeology and groundwater chemistry

8 of the Oderbruch have been intensely investigated [18-21]. Surface elevation of the investigated area is $2-3 \mathrm{~m}$ above sea level. The area lies mainly below the river water level, and the river base is highly permeable because it consists of coarse sand and gravel. Consequently, river water is permanently infiltrating into the shallow aquifer as shown in Fig. 2. The aquifer consists of fine to medium sized sands and the thickness is about $20-30 \mathrm{~m}$ on the average. It is underlain by a glacial till (thickness $\sim 120 \mathrm{~m}$ ) and overlain by an alluvial loam (thickness $0.4-4.0 \mathrm{~m}$ ). Along the river banks of the area, the aquifer is confined up to about $3 \mathrm{~km}$ inland (Figs. 1 and 2) and recharged by river water infiltration only.

Six groundwater samples of $100 \mathrm{ml}$ were obtained from confined area in September 2003. Sampling points are located along the major groundwater flow direction (Fig. 1). At each point, groundwater samples were obtained from piezometers at two depths (5-7 $\mathrm{m}$ and 19-21 m below ground surface). These depths correspond to upper and lower parts of the aquifer. Since the groundwater ages of the same sampling depths had been estimated by the ${ }^{3} \mathrm{H} /{ }^{3} \mathrm{He}$ method in $2001[18,21]$, this area was well suited for this study.

\subsection{Sample preparation and measurements}

Groundwater samples were analyzed for $\mathrm{Cl}^{-}$and ${ }^{36} \mathrm{Cl}$. All samples were filtered through 0.20 $\mu \mathrm{m}$ membrane filter (DISMIC-25cs, Advantec, Tokyo, Japan). The $\mathrm{Cl}^{-}$concentrations of aliquots were determined by ion chromatography (Dionex DX-500).

For ${ }^{36} \mathrm{Cl}$ AMS analysis, groundwater samples were prepared as AgCl. Excluding samples with high $\mathrm{Cl}^{-}$concentrations (generally more than $50 \mathrm{mg} / \mathrm{l}$ ), each groundwater sample 
1 containing more than $1 \mathrm{mg}$ of $\mathrm{Cl}$ was heated on a hot plate to concentrate it to $10-20 \mathrm{ml}$.

2 Figure 3 shows the sample preparation scheme employed in this study. For the purpose of 3 eliminating the isobaric interference from ${ }^{36} \mathrm{~S}$ in the ${ }^{36} \mathrm{Cl}$ AMS measurement, a sulfur reduction 4 process was included in the sample preparation scheme. The procedure was performed in an 5 air-conditioned room to prevent the addition of sulfur contamination and also under dark 6 conditions to avoid decomposition of the AgCl.

7 At first, each sample was acidified with $13 \mathrm{M} \mathrm{HNO}_{3}$, and then $0.3 \mathrm{M} \mathrm{AgNO}_{3}$ solution was 8 added to precipitate $\mathrm{AgCl}$. The AgCl precipitate was separated by centrifugation and dissolved 9 in $3 \mathrm{M} \mathrm{NH}_{4} \mathrm{OH}$. In order to precipitate sulfur (in the form of $\mathrm{SO}_{4}{ }^{2-}$ ) as $\mathrm{BaSO}_{4}$, saturated $\mathrm{Ba}\left(\mathrm{NO}_{3}\right)_{2}$ solution was added. The $\mathrm{BaSO}_{4}$ precipitate was removed by filtration and the filtrate was acidified by the addition of $13 \mathrm{M} \mathrm{HNO}_{3}$ to precipitate $\mathrm{AgCl}$ again. This sulfur reduction process was repeated. After these steps, the $\mathrm{AgCl}$ precipitate was re-dissolved and re-precipitated in order to further exclude remaining impurities. Finally, the AgCl precipitate was washed three times with $0.01 \mathrm{M} \mathrm{HNO}_{3}$ and twice with $99.5 \% \mathrm{C}_{2} \mathrm{H}_{5} \mathrm{OH}$, and then dried in the oven at $130^{\circ} \mathrm{C}$ for 3 hours. The overall chemical yield of chlorine was, on the average, about 80\%. For subsequent AMS measurements, a benzene solution saturated with fullerene $\left(C_{60}\right)$ was added to each sample ( 10 $\mu \mathrm{l}$ per $1 \mathrm{mg}$ of $\mathrm{AgCl}$ ) and the sample was re-dried just before the target pressing.

The ${ }^{36} \mathrm{Cl} / \mathrm{Cl}$ ratios of the samples were measured by AMS at the Tandem Accelerator Complex, University of Tsukuba [22]. At the Tsukuba AMS system, which was developed on the 12UD Pelletron tandem accelerator, the tri-carbon molecular ion $\left({ }^{12} \mathrm{C}_{3}^{-}\right)$is used as a pilot beam to stabilize the terminal voltage of the tandem accelerator (9 MV for ${ }^{36} \mathrm{Cl}$-AMS). Due to the addition of the saturated fullerene solution to each sample as mentioned above, ${ }^{12} \mathrm{C}_{3}{ }^{-}$ions are produced in the ion source concurrently with $\mathrm{Cl}^{-}$ions. Stable ${ }^{35} \mathrm{Cl}^{-}$ions are measured as a current using a Faraday cup just after a $120^{\circ}$ magnet just downstream of the ion source, while the ${ }^{36} \mathrm{Cl}^{-}$ions of interest are injected into the accelerator with ${ }^{12} \mathrm{C}_{3}^{-}$and accelerated. Through two steps of charge changing, ${ }^{36} \mathrm{Cl}^{13+}$ ions are transported to a $\Delta E$ - $E$ detector, distinguished from ${ }^{36} \mathrm{~S}^{13+}$ background and counted. 
After ${ }^{36} \mathrm{~S}$ background correction using a blank sample prepared from a $\mathrm{NaCl}$ reagent, the ${ }^{36} \mathrm{Cl}^{35} \mathrm{Cl}^{-}$(counts/ $\mu \mathrm{C}$ ) ratio derived from such measurements of a sample is normalized to the counts/ $\mu \mathrm{C}$ ratio obtained for a standard sample yielding the ${ }^{36} \mathrm{Cl} / \mathrm{Cl}$ ratio of the sample. The standard samples are prepared by dilution of the NIST ${ }^{36} \mathrm{Cl}$ standard (SRM 4943) with $\mathrm{NaCl}$ reagent [23]. The calculated ${ }^{36} \mathrm{Cl} / \mathrm{Cl}$ ratio of the standard sample is $4.47 \times 10^{-11}$. At the Tsukuba AMS system, the background level of ${ }^{36} \mathrm{Cl} / \mathrm{Cl}$ measurement is $2 \times 10^{-14}$ [22]. Details of the

${ }^{36} \mathrm{Cl} / \mathrm{Cl}$ calculations and measurement errors have been described previously [23].

In this study, the ${ }^{36} \mathrm{Cl}$ data are used in the form of ${ }^{36} \mathrm{Cl} / \mathrm{Cl}$ ratios; these ratios are used in further discussions rather than ${ }^{36} \mathrm{Cl}$ concentrations in order to minimize the possible influences of dilution and/or evaporation processes on the interpretation of the results.

\section{Results and discussion}

Table 1 lists $\mathrm{Cl}^{-}$concentrations, ${ }^{36} \mathrm{Cl}$ data and ${ }^{3} \mathrm{H} /{ }^{3} \mathrm{He}$ data $[18,21]$ for the samples. The $\mathrm{Cl}^{-}$ concentrations decrease from $\sim 100 \mathrm{mg} / \mathrm{l}$ to $24 \mathrm{mg} / \mathrm{l}$ with distance from the Oder.

One possible cause of the decrease is mixing between the groundwater and infiltrating water from the surface. Although the aquifer is essentially confined up to $2144 \mathrm{~F} \& \mathrm{~T}$, the groundwater is recharged to some extent by infiltration through the unsaturated zone (50-70 mm/year [18]). The $\mathrm{Cl}^{-}$concentration in the infiltrating water would be $2.1-9.5 \mathrm{mg} / \mathrm{l}$. These values were calculated from $434 \mathrm{~mm}$ of mean annual precipitation (1951-1980) [18] with $0.34-1.1 \mathrm{mg} / \mathrm{l} \mathrm{of}$ $\mathrm{Cl}^{-}$concentration (south Germany [24]), and 50-70 mm of mean annual recharge rate [18]. The mixing rate of the infiltrating water would be $78-84 \%$, when the infiltration is responsible for all of the reduction in $\mathrm{Cl}^{-}$concentrations.

However, the mean annual recharge rate $(50-70 \mathrm{~mm})$ is very small compared to the thickness of the aquifer ( $20 \mathrm{~m}$; Fig. 2). Accordingly, the mixing of $78-84 \%$ of the infiltrating water should not have occurred. Other phenomena such as change in evaporation rate may have caused the variation in $\mathrm{Cl}^{-}$concentration of the Oder. This kind of variation has no effect on ${ }^{36} \mathrm{Cl} / \mathrm{Cl}$ ratio.

The possible mixing rate of the infiltrating water would be $\sim 18 \%$ as calculated from 70 
$1 \mathrm{~mm} /$ year of recharge rate for 50 years (as discussed later) and $20 \mathrm{~m}$ of the thickness of the 2 aquifer. In this case, $\mathrm{Cl}^{-}$derived from the infiltrating water is only $0.5-2 \%$ of total $\mathrm{Cl}^{-}$in the 3 groundwater. This contribution would not cause serious effect to the original ${ }^{36} \mathrm{Cl} / \mathrm{Cl}$ ratio. 4 Therefore, any influence of the $\mathrm{Cl}^{-}$concentration variations on the ${ }^{36} \mathrm{Cl} / \mathrm{Cl}$ ratios of groundwater 5 samples does not appear to be a significant driver of the observed variations of the ${ }^{36} \mathrm{Cl} / \mathrm{Cl}$ ratios 6 of the six samples.

In this study, ages derived in a previous study using the ${ }^{3} \mathrm{H} /{ }^{3} \mathrm{He}$ method have been assigned 8 to the groundwater samples $[18,21]$. The ${ }^{3} \mathrm{H} /{ }^{3} \mathrm{He}$ method has been applied effectively in many 9 groundwater studies to date modern groundwater [4,25-27]. The ${ }^{3} \mathrm{H} /{ }^{3} \mathrm{He}$ ages were calculated as follows [28]:

$$
t=\frac{T_{1 / 2}}{\ln 2} \ln \left(1+\frac{\left[{ }^{3} \mathrm{He}_{\text {trit }}\right]}{\left[{ }^{3} \mathrm{H}\right]}\right)
$$

where $t$ is the ${ }^{3} \mathrm{H} /{ }^{3} \mathrm{He}$ age (years), $T_{1 / 2}$ is the half-life of ${ }^{3} \mathrm{H}\left(12.33\right.$ years), $\left[{ }^{3} \mathrm{H}\right]$ is the ${ }^{3} \mathrm{H}$ concentration (TU; 1 TU means one ${ }^{3} \mathrm{H}$ atom in $10{ }^{18}{ }^{1} \mathrm{H}$ atoms), and $\left[{ }^{3} \mathrm{He}_{\text {trit }}\right]$ is the tritiogenic ${ }^{3}$ He concentration (TU).

From the results of the ${ }^{3} \mathrm{H} /{ }^{3} \mathrm{He}$ dating $[18,21]$, the residence times of these groundwater samples range from a few years to $\sim 50$ years. In the ${ }^{3} \mathrm{H} /{ }^{3} \mathrm{He}$ dating study $[18,21]$, dispersion and diffusion of ${ }^{3} \mathrm{He}$ were not considered; accordingly, these factors were also not considered and assumed to be unimportant for ${ }^{36} \mathrm{Cl}$ in this study. Figure 4 shows the ${ }^{36} \mathrm{Cl} / \mathrm{Cl}$ ratios and initial tritium concentrations (sum of ${ }^{3} \mathrm{H}$ and tritiogenic ${ }^{3} \mathrm{He}$ ) plotted against the distance from the Oder. The ${ }^{36} \mathrm{Cl} / \mathrm{Cl}$ ratios and the initial tritium concentrations showed similar variations with distance from the Oder (i.e., along the major groundwater flow direction). High values derived from the ${ }^{36} \mathrm{Cl}$ and ${ }^{3} \mathrm{H}$ bomb pulses were observed in two samples (1/01 $\mathrm{F}$ and 1/01 T; $2139 \mathrm{~m}$ away from the river). It should be noted that sample $9561 \mathrm{~F}$ was somewhat enhanced only in initial tritium concentration. This may be due to the timing difference between the ${ }^{36} \mathrm{Cl}$ and ${ }^{3} \mathrm{H}$ fallout pulses, with the ${ }^{36} \mathrm{Cl}$ peak appearing significantly earlier than that of ${ }^{3} \mathrm{H}$. Although the limited number of data points does not allow definitive conclusions, this result suggests that ${ }^{36} \mathrm{Cl}$ was transported with groundwater flow in almost the same way as ${ }^{3} \mathrm{H}$. 
To allow comparison of these data to the fallout history of bomb-produced ${ }^{36} \mathrm{Cl}$, the ${ }^{36} \mathrm{Cl} / \mathrm{Cl}$ ratios of the Oderbruch samples were converted into fallout values using the following equation [29]:

$$
R=\frac{F \times 3.15 \times 10^{7}}{P \times 10^{-3} \times[\mathrm{Cl}]_{\mathrm{p}} \times 6.022 \times 10^{23} / 35.45}
$$

where $R$ is the measured ${ }^{36} \mathrm{Cl} / \mathrm{Cl}$ ratio (in unit of $10^{-15}$ ), $F$ is the ${ }^{36} \mathrm{Cl}$ fallout (atoms $\mathrm{m}^{-2} \mathrm{~s}^{-1}$ ), $P$ is the mean annual precipitation (mm), and $[\mathrm{Cl}]_{\mathrm{p}}$ is the $\mathrm{Cl}^{-}$concentration in the precipitation (mg/l).

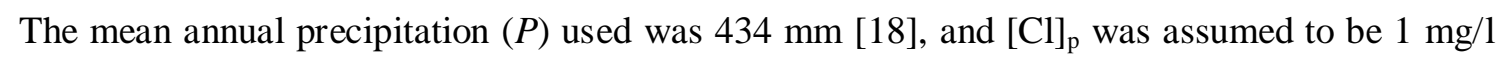
(cf. 0.34-1.1 mg/l; south Germany [24]). The estimated fallout values from the Oderbruch samples and measured fallout values at Dye-3 [12] are plotted together in Fig. 5. The ages assigned to the Oderbruch groundwater samples are from the ${ }^{3} \mathrm{H} /{ }^{3} \mathrm{He}$ ages (Table 1) using 2003 as year zero.

As Fig. 5 shows, the trends of the estimated fallout values and the Dye- 3 values are in reasonable agreement except for one sample (2144 T). Although the ${ }^{3} \mathrm{H} /{ }^{3} \mathrm{He}$ age of the $2144 \mathrm{~T}$ sample was calculated to be 42 years, this sample’s initial tritium concentration is very low (3.2 TU; Table 1). This indicates that the $2144 \mathrm{~T}$ sample does not contain bomb pulse ${ }^{3} \mathrm{H}$, and hence, was composed of pre-bomb waters with an age of $>50$ years. Therefore, as shown by the arrow in Fig. 5, the $2144 \mathrm{~T}$ sample should actually be plotted at about the time of the $2144 \mathrm{~F}$ sample. With this correction, the variations in the estimated fallout values are consistent with the trends in the fallout at Dye-3.

Although the Oderbruch samples do not capture the most diagnostic portion of the ${ }^{36} \mathrm{Cl}$ fallout pulse, the results clearly suggest that the distribution of ${ }^{36} \mathrm{Cl}$ in the Oberbruch groundwaters corresponds to the bomb pulse. Consequently, the Oberburch results obtained here support the contention that the ${ }^{36} \mathrm{Cl}$ bomb pulse can be used as an effective environmental tracer in groundwater studies.

From the results obtained for the four pre- and post-bomb pulse samples, the pre-bomb background ${ }^{36} \mathrm{Cl} / \mathrm{Cl}$ ratio in the Oder basin, which extends from about $49^{\circ} \mathrm{N}$ to $53^{\circ} \mathrm{N}$ (including areas upstream of the Oderbruch), is estimated to be $7-9 \times 10^{-14}$. These four results also suggest 
1 that the ${ }^{36} \mathrm{Cl} / \mathrm{Cl}$ ratio returned to pre-bomb levels by $\sim 1980$ (about 20 years ago), which is

2 consistent with the trends in the Dye-3 ice core data [12]. It is worth noting that the two samples

3 with somewhat higher ${ }^{36} \mathrm{Cl} / \mathrm{Cl}$ ratios in Fig. 5 (1/01 F and 1/01 T) correspond to the tail part of 4 the bomb pulse.

Priller et al. [30] measured the ${ }^{36} \mathrm{Cl} / \mathrm{Cl}$ ratios of wine samples spanning 1930-1980 from the 6 Rheingau region in western Germany (about $50^{\circ} \mathrm{N}$ ). Their results have been interpreted as 7 reflecting the ${ }^{36} \mathrm{Cl} / \mathrm{Cl}$ ratios of soil waters in each sampled year. The mean ${ }^{36} \mathrm{Cl} / \mathrm{Cl}$ ratio they 8 obtained for the pre-bomb period was about $(5.1 \pm 2.2) \times 10^{-14}$ (which is slightly lower than the 9 result obtained in this study), while their peak value was $2-4 \times 10^{-12}$ for the years $1959-1961$. On the basis of Priller et al.'s results and the concordance between the Oberbruch and Dye-3 results (and if dispersion and mixing effects are negligible), the results obtained in this study suggest that the groundwater ${ }^{36} \mathrm{Cl}$ bomb peak in the Oderbruch should reach a peak at a distance of $\sim 2.7 \mathrm{~km}$ from the Oder and the peak ${ }^{36} \mathrm{Cl} / \mathrm{Cl}$ ratio value should be on the order of $10^{-12}$.

\section{Conclusions and outlook}

${ }^{36} \mathrm{Cl} / \mathrm{Cl}$ ratios of groundwater samples were measured by AMS to evaluate the potential use of ${ }^{36} \mathrm{Cl}$ as a dating tool for modern groundwaters. The ${ }^{36} \mathrm{Cl}$ fallout values estimated from the ${ }^{36} \mathrm{Cl} / \mathrm{Cl}$ ratios of ${ }^{3} \mathrm{H} /{ }^{3} \mathrm{He}$ dated Oderbruch samples show reasonable agreement with ${ }^{36} \mathrm{Cl}$ fallout data from the Dye-3 ice core. This provides support for the contention that the variations of ${ }^{36} \mathrm{Cl}$ in groundwaters reflect the input of bomb pulse ${ }^{36} \mathrm{Cl}$, and hence, that the variations of ${ }^{36} \mathrm{Cl} / \mathrm{Cl}$ in modern groundwaters should reveal groundwater ages and flow systems in a region.

In contrast to the ${ }^{3} \mathrm{H} /{ }^{3} \mathrm{He}$ method, the utilization of ${ }^{36} \mathrm{Cl}$ in such studies requires spatially extended sampling in order to map out the ${ }^{36} \mathrm{Cl}$ bomb pulse in the regional groundwaters. However, because of its geochemical behavior, ${ }^{36} \mathrm{Cl}$ can be utilized in both the unsaturated zone and the saturated zone. In the utilization of ${ }^{36} \mathrm{Cl}$ in groundwater dating studies, the possible effects of dispersion on the ${ }^{36} \mathrm{Cl}$ concentrations and ${ }^{36} \mathrm{Cl} / \mathrm{Cl}$ ratios in the groundwater should be evaluated. In this regard, further investigations, involving denser sampling of the region, are underway in the Oderbruch. 


\section{Acknowledgements}

3 We are grateful to the technical staff of the Tandem Accelerator Complex, University of 4 Tsukuba for their skillful operation of the accelerator. We thank Dr. Thomas A. Brown (LLNL), 5 Dr. Gregory Nimz (LLNL) and anonymous reviewers for their helpful comments. We also thank 6 Dr. Yuki Matsushi (University of Tsukuba) for his valuable comments. Their many suggestions 7 greatly improved the paper. This study was partly supported by Grants-in-Aid for Scientific 8 Research (Nos. 13680619, 14350038, 15656021 and 16201005) from the Ministry of Education, 9 Culture, Sports, Science and Technology, Japan.

\section{References}

[1] B.C.E. Egboka, J.A. Cherry, R.N. Farvolden, E.O. Frind, J. Hydrol. 63 (1983) 51.

13 [2] W.D. Robertson, J.A. Cherry, Water Resour. Res. 25 (1989) 1097.

14 [3] R.B. Firestone, Table of Isotopes, eighth ed., Wiley, New York, 1996.

[4] P. Schlosser, M. Stute, H. Dörr, C. Sonntag, K.O. Münnich, Earth Planet. Sci. Lett. 89 (1988) 353.

17 [5] E. Busenberg, L.N. Plummer, Water Resour. Res. 28 (1992) 2257.

18 [6] E. Busenberg, L.N. Plummer, Water Resour. Res. 36 (2000) 3011.

19 [7] W.M. Smethie, Jr., D.K. Solomon, S.L. Schiff, G.G. Mathieu, J. Hydrol. 130 (1992) 279.

20 [8] H.W. Bentley, F.M. Phillips, S.N. Davis, S. Gifford, D. Elmore, L.E. Tubbs, H.E. Gove, $21 \quad$ Nature 300 (1982) 737.

22 [9] H.W. Bentley, F.M. Phillips, S.N. Davis, in: P. Fritz, J.-Ch. Fontes (Eds.), Handbook of 23 Environmental Isotope Geochemistry, Vol. 2, Elsevier, Amsterdam, 1986, p. 427.

24 [10] F.M. Phillips, in: P.G. Cook, A.L. Herczeg (Eds.), Environmental Tracers in Subsurface 25 Hydrology, Kluwer, Boston, 2000, p. 299.

26 [11] D. Elmore, L.E. Tubbs, D. Newman, X.Z. Ma, R. Finkel, K. Nishiizumi, J. Beer, H. 27 Oeschger, M. Andree, Nature 300 (1982) 735.

28 [12] H.-A. Synal, J. Beer, G. Bonani, M. Suter, W. Wölfli, Nucl. Instr. Meth. B 52 (1990) 483. 
1 [13] H.W. Bentley, F.M. Phillips, S.N. Davis, M.A. Habermehl, P.L. Airey, G.E. Calf, D. Elmore,

2 H.E. Gove, T. Torgersen, Water Resour. Res. 22 (1986) 1991.

3 [14] F.M. Phillips, H.W. Bentley, S.N. Davis, D. Elmore, G.B. Swanick, Water Resour. Res. 22 $4 \quad$ (1986) 2003.

5 [15] F.M. Phillips, J.L. Mattick, T.A. Duval, D. Elmore, P.W. Kubik, Water Resour. Res. 24 $6 \quad(1988) 1877$.

7 [16] P.G. Cook, I.D. Jolly, F.W. Leaney, G.R. Walker, Water Resour. Res. 30 (1994) 1709.

8 [17] W. Balderer, H.-A. Synal, J. Deak, Environ. Geol. 46 (2004) 755.

9 [18] G. Massmann, Ph.D. Thesis, Free University of Berlin, 2002.

10 [19] G. Massmann, M. Tichomirowa, C. Merz, A. Pekdeger, J. Hydrol. 278 (2003) 231.

11 [20] G. Massmann, A. Pekdeger, C. Merz, Appl. Geochem. 19 (2004) 863.

12 [21] J. Sültenfuß, G. Massmann, Grundwasser 9 (2004) 221 (in German with English abstract).

13 [22] Y. Nagashima, R. Seki, T. Takahashi, D. Arai, Nucl. Instr. Meth. B 172 (2000) 129.

14 [23] Y. Nagashima, R. Seki, T. Matsuhiro, T. Takahashi, K. Sasa, K. Sueki, M. Hoshi, S. Fujita, 15 K. Shizuma, H. Hasai, Nucl. Instr. Meth. B 223-224 (2004) 782.

16 [24] C. Scheffel, A. Blinov, S. Massonet, H. Sachsenhauser, C. Stan-Sion, J. Beer, H.-A. Synal, 17 P.W. Kubik, M. Kaba, E. Nolte, Geophys. Res. Lett. 26 (1999) 1401.

18 [25] N. Takaoka, Y. Mizutani, Earth Planet. Sci. Lett. 85 (1987) 74.

19 [26] R.J. Poreda, T.E. Cerling, D.K. Salomon, J. Hydrol. 103 (1988) 1.

20 [27] P. Schlosser, M. Stute, C. Sonntag, K.O. Münnich, Earth Planet. Sci. Lett. 94 (1989) 245.

21 [28] L.N. Tolstikhin, I.L. Kamenskiy, Geochem. Int. 6 (1969) 810.

22 [29] J.N. Andrews, W.M. Edmunds, P.L. Smedley, J.-Ch. Fontes, L.K. Fifield, G.L. Allan, Earth 23 Planet. Sci. Lett. 122 (1994) 159.

24 [30] A. Priller, G. Korschinek, E. Nolte, W. Rühm, Nucl. Instr. Meth. B 52 (1990) 618. 


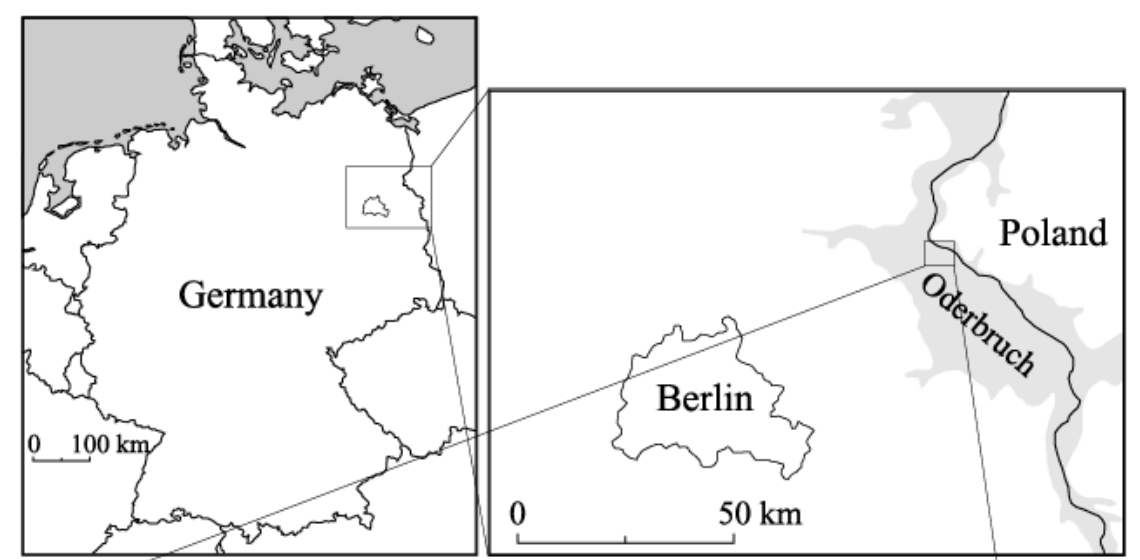

4

5 Fig. 1. Location of the Oderbruch polder and groundwater sampling points along the projection

6 line (modified from Sültenfuß and Massmann [21]). Also indicated is groundwater flow 7 direction [18].

8 


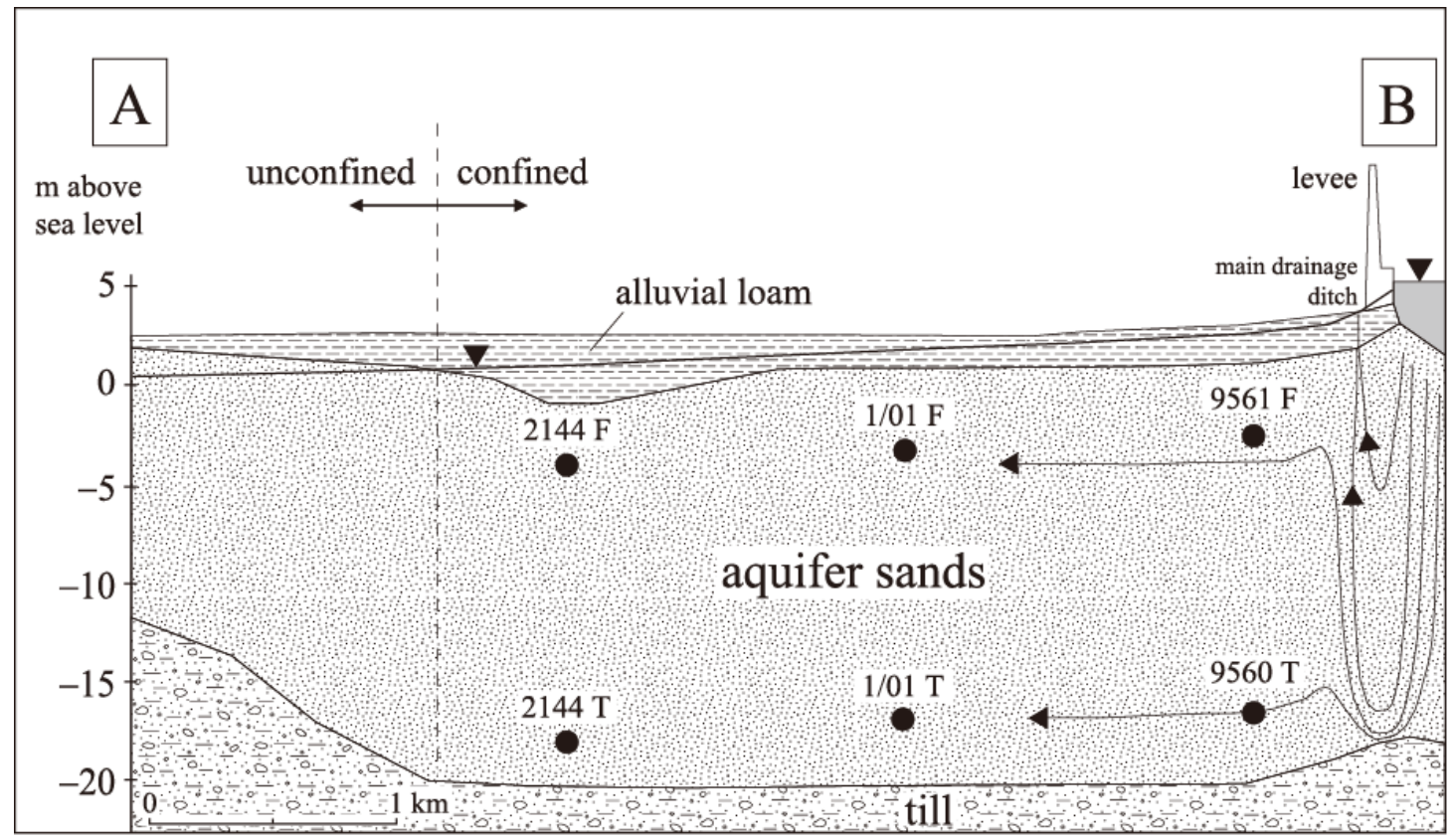

4

5 Fig. 2. Cross section along the projection line with major hydrological units (modified from 6 Sültenfuß and Massmann [21]). The projection line is shown in Fig. 1. The arrows in the aquifer 7 show groundwater flow paths. Black circles indicate the depths of filter screens of piezometers. 8 


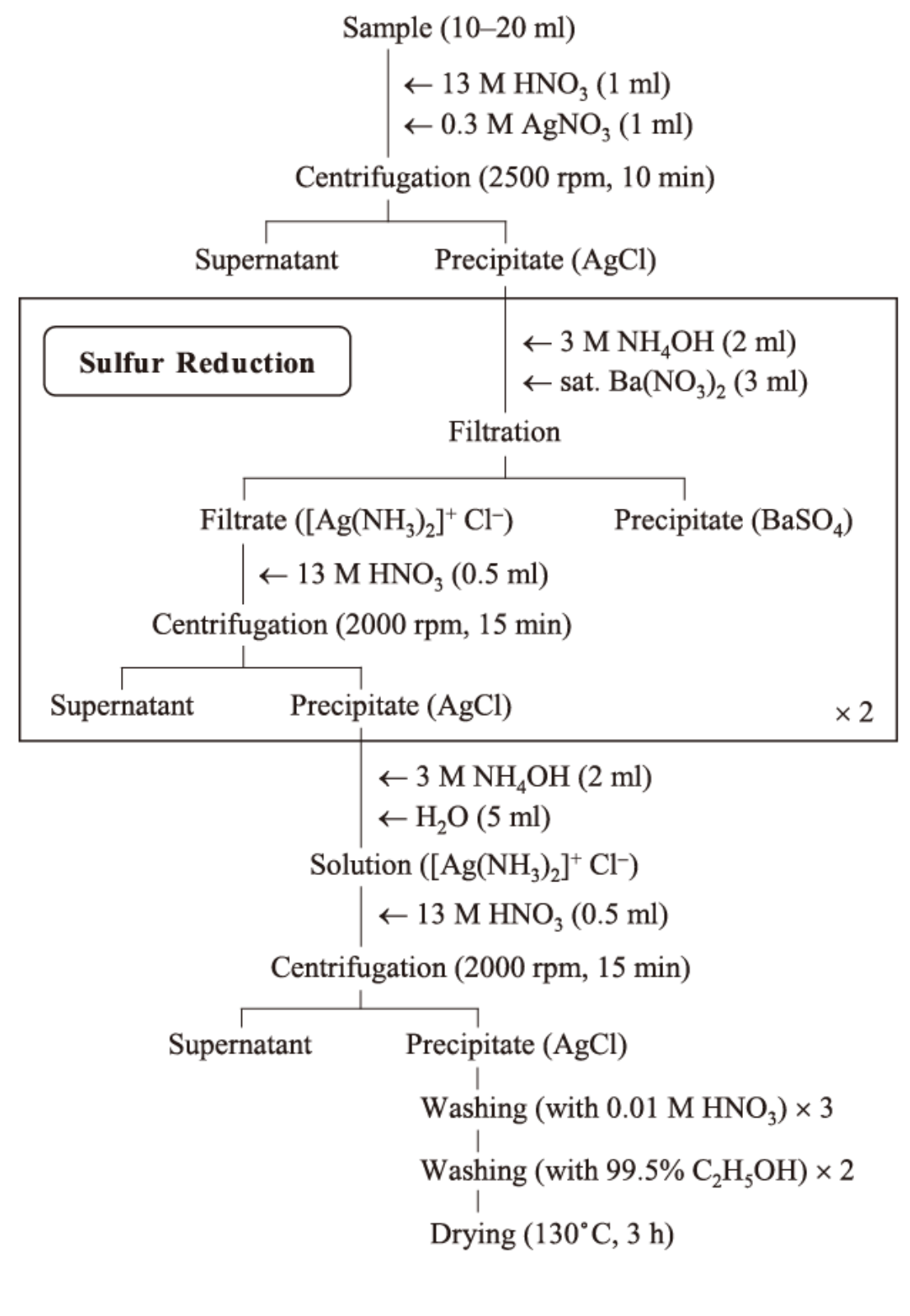

5 Fig. 3. Sample preparation scheme for ${ }^{36} \mathrm{Cl}$ AMS (accelerator mass spectrometry). 6 

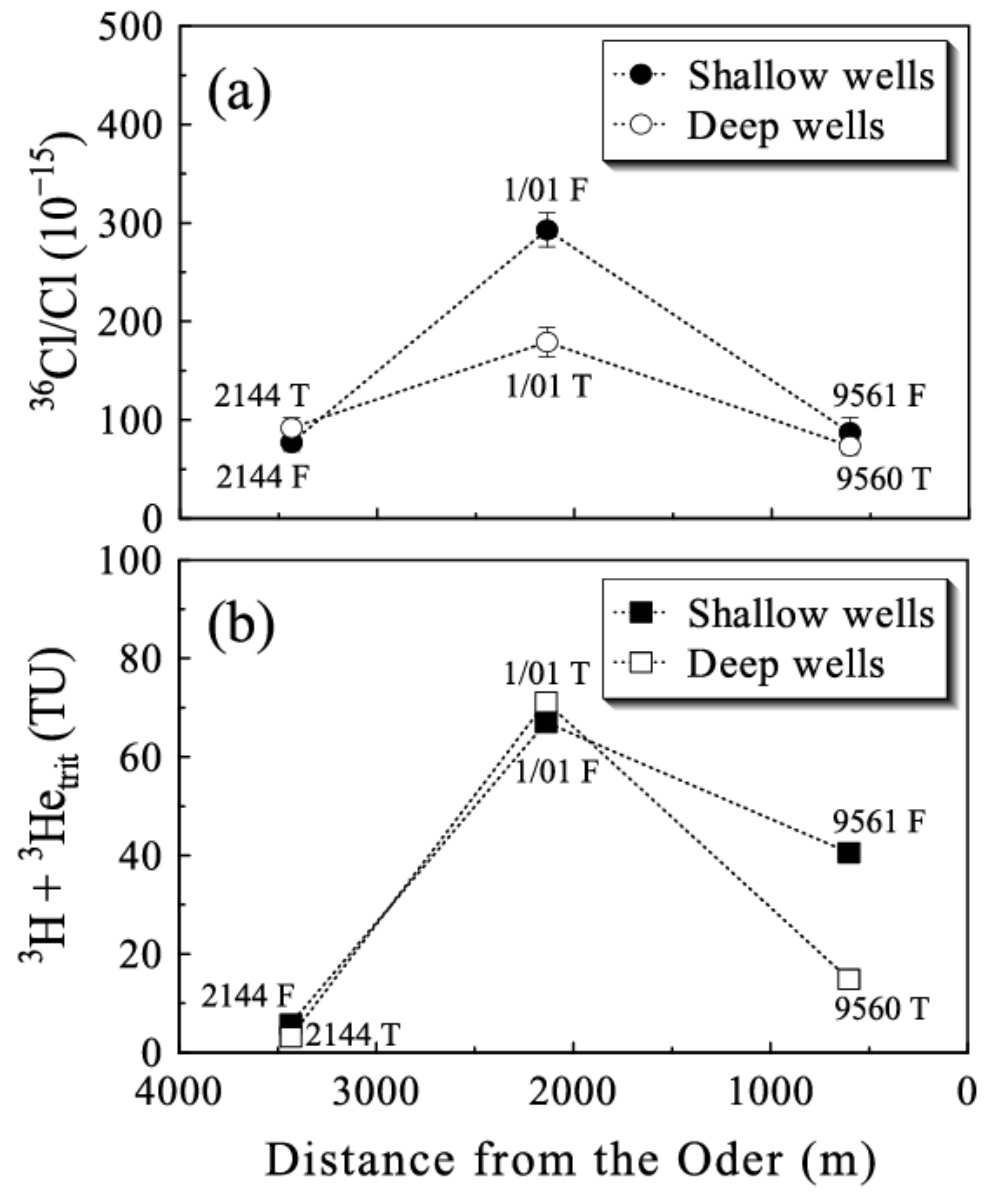

5 Fig. $4 .{ }^{36} \mathrm{Cl} / \mathrm{Cl}$ ratios and initial tritium concentrations $[18,21]$ for the Oderbruch samples as a 6 function of the distance from the Oder. (a) ${ }^{36} \mathrm{Cl} / \mathrm{Cl}$ ratio. (b) Initial tritium concentration. 


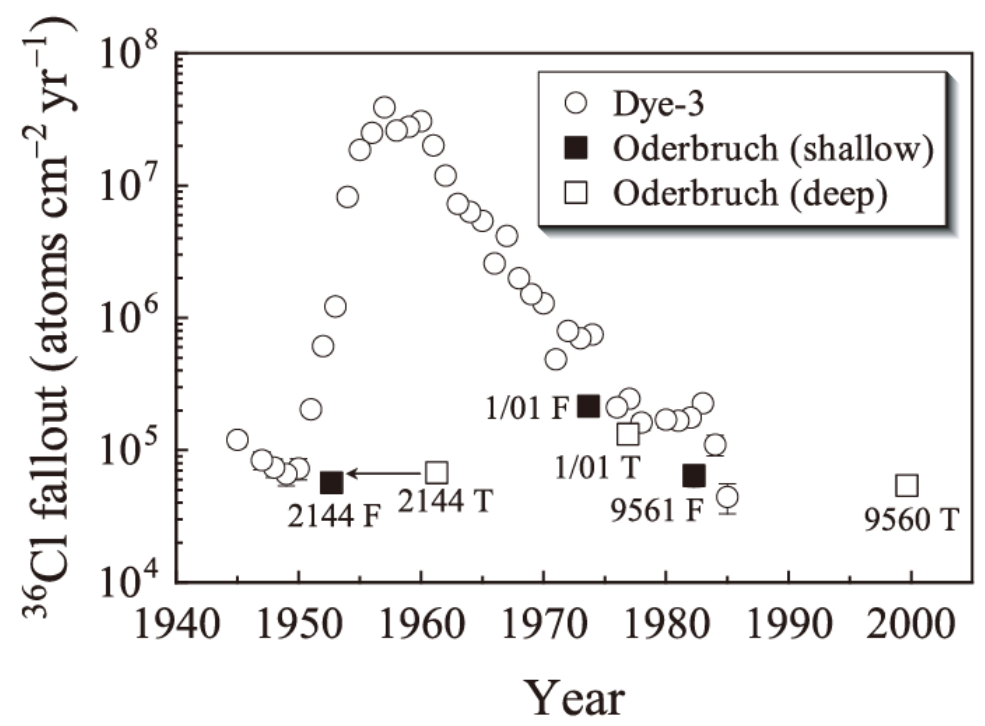

4

5 Fig. 5. Comparison of measured ${ }^{36} \mathrm{Cl}$ fallout values from Dye-3 ice core [12] and the estimated 6 fallout values from the Oderbruch groundwater samples. The estimated fallout values were 7 calculated using Eq. (2) and presented as annual fluxes (atoms $\mathrm{cm}^{-2} \mathrm{yr}^{-1}$ ). The ages assigned to 8 the Oderbruch samples are from the ${ }^{3} \mathrm{H} /{ }^{3} \mathrm{He}$ ages (Table 1) using 2003 as year zero. The age of $92144 \mathrm{~T}$ sample should be older as indicated by the arrow; the sample has low initial tritium 10 concentration (3.2 TU; Table 1). 
Table 1

Measured $\mathrm{Cl}^{-}$concentrations, ${ }^{36} \mathrm{Cl} / \mathrm{Cl}$ ratios and ${ }^{36} \mathrm{Cl}$ concentrations for the Oderbruch samples

\begin{tabular}{lcllccccc}
\hline Sample & $\begin{array}{c}\text { Distance* } \\
(\mathrm{m})\end{array}$ & $\begin{array}{l}\text { Screen depth } \\
(\text { masl }) \dagger\end{array}$ & $\begin{array}{l}\mathrm{Cl}^{-} \\
(\mathrm{mg} / \mathrm{l})\end{array}$ & $\begin{array}{c}{ }^{36} \mathrm{Cl} / \mathrm{Cl} \\
\left(10^{-15}\right)\end{array}$ & $\begin{array}{c}{ }^{36} \mathrm{Cl} \\
\left(10^{6} \text { atoms/l) }\right.\end{array}$ & $\begin{array}{c}{ }^{3} \mathrm{H} \\
(\mathrm{TU})\end{array}$ & $\begin{array}{c}{ }^{3} \mathrm{He}_{\text {trit }} \neq \\
(\mathrm{TU})\end{array}$ & $\begin{array}{c}{ }^{3} \mathrm{H} /{ }^{3} \mathrm{He} \\
\text { age (a) }\end{array}$ \\
\hline $9561 \mathrm{~F}$ & 604 & -2.4 & 104.9 & $87 \pm 15$ & $156 \pm 27$ & 12.8 & 27.8 & 21 \\
$1 / 01 \mathrm{~F}$ & 2139 & -3.5 & 61.9 & $293 \pm 17$ & $308 \pm 18$ & 13.0 & 54.0 & 29 \\
$2144 \mathrm{~F}$ & 3434 & -4.3 & 22.7 & $77 \pm 9$ & $30 \pm 3$ & 0.4 & 5.5 & 50 \\
$9560 \mathrm{~T}$ & 604 & -16.8 & 94.6 & $73 \pm 9$ & $118 \pm 14$ & 12.3 & 2.5 & 3 \\
$1 / 01 \mathrm{~T}$ & 2139 & -17.0 & 76.4 & $179 \pm 15$ & $233 \pm 19$ & 16.6 & 54.6 & 26 \\
$2144 \mathrm{~T}$ & 3434 & -17.9 & 25.4 & $92 \pm 11$ & $40 \pm 5$ & 0.3 & 2.9 & 42 \\
\hline
\end{tabular}

Concentrations of ${ }^{3} \mathrm{H}$ and ${ }^{3} \mathrm{He}$ trit, and ${ }^{3} \mathrm{H} /{ }^{3} \mathrm{He}$ ages are from Massmann [18] and Sültenfuß and Massmann [21].

*Distance from the Oder.

$\dagger \mathrm{m}$ above sea level.

$\ddagger$ Tritiogenic ${ }^{3} \mathrm{He}$. 